University of South Florida

DIGITAL COMMONS

Digital Commons @ University of

@ UNIVERSITY OF SOUTH FLORIDA

South Florida

January 2013

\title{
Evaluating Check-In Check-Out with Peer Tutors for Children with Attention Maintained Problem Behaviors
}

Sindy Sanchez

University of South Florida, ssanche5@mail.usf.edu

Follow this and additional works at: https://digitalcommons.usf.edu/etd

Part of the Behavioral Disciplines and Activities Commons

\section{Scholar Commons Citation}

Sanchez, Sindy, "Evaluating Check-In Check-Out with Peer Tutors for Children with Attention Maintained Problem Behaviors" (2013). USF Tampa Graduate Theses and Dissertations.

https://digitalcommons.usf.edu/etd/4762

This Thesis is brought to you for free and open access by the USF Graduate Theses and Dissertations at Digital Commons @ University of South Florida. It has been accepted for inclusion in USF Tampa Graduate Theses and Dissertations by an authorized administrator of Digital Commons @ University of South Florida. For more information, please contact digitalcommons@usf.edu. 
Evaluating Check-In Check-Out with Peer Tutors for Children with Attention Maintained Problem Behaviors

by

\begin{abstract}
Sindy Sanchez
A thesis submitted in partial fulfillment of the requirements for the degree of Master of Arts

Department of Child and Family Studies College of Behavioral and Community Sciences

University of South Florida
\end{abstract}

Major Advisor: Dr. Raymond Miltenberger, Ph.D., BCBA-D

Dr. Kwang-Sun Blair, Ph.D., BCBA

Dr. Donald Kincaid Ed.D

Date of Approval:

June 21, 2013

Keywords: Behavior Education Plan (BEP); Daily Report Card (DRC); targeted intervention; secondary intervention; multi-tiered system of supports; school-wide positive behavior support

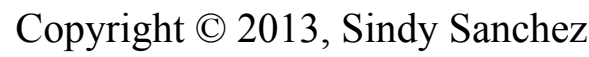




\section{Table of Contents}

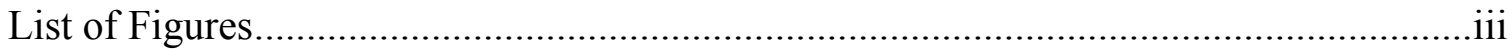

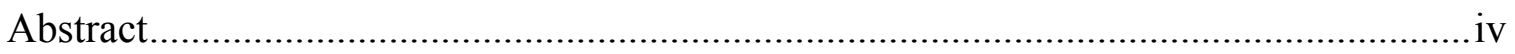

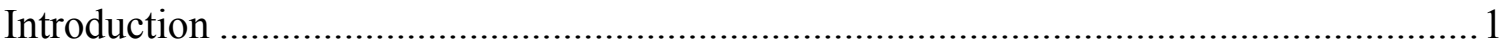

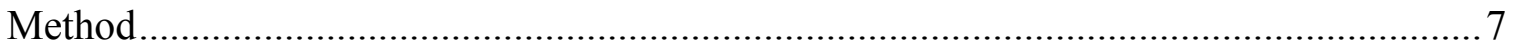

Participants and Setting ........................................................................... 7

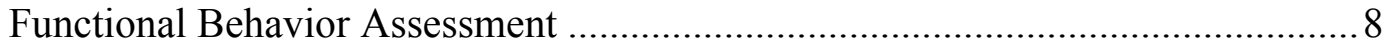

Data Collection and Interobserver Agreement ............................................. 9

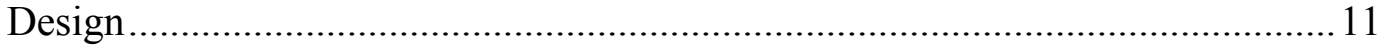

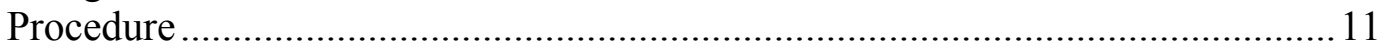

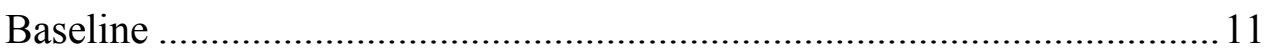

Check-in Check-out - peer .......................................................... 11

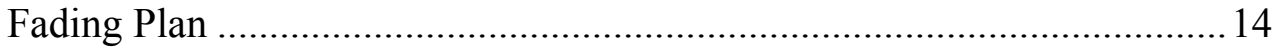

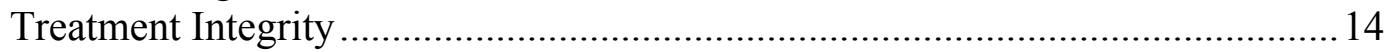

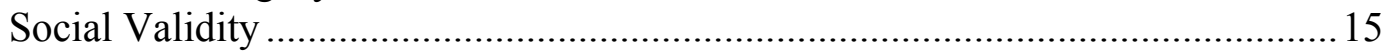

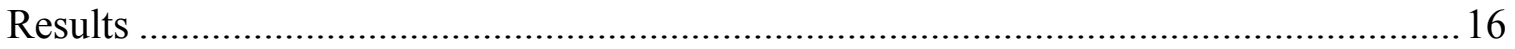

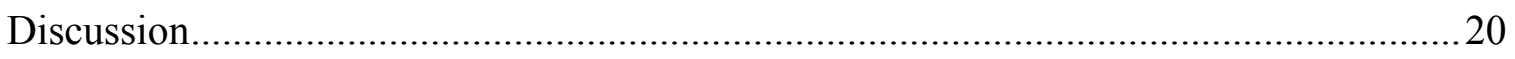

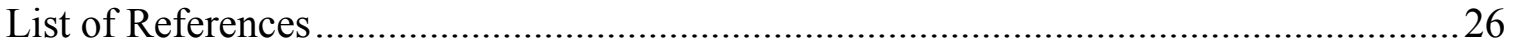

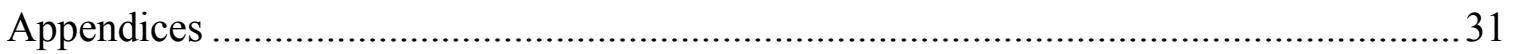

Appendix A - Teacher Nomination Form ....................................................... 31

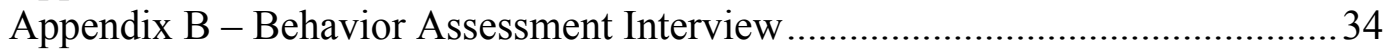

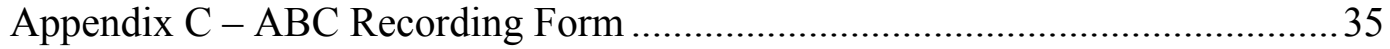

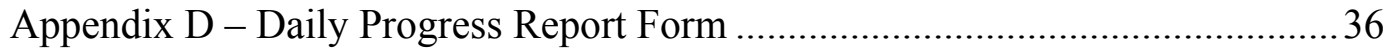

Appendix E - Treatment Fidelity Checklist ................................................... 37

Appendix F - Social Validity Questionnaires .............................................. 39 


\section{List of Figures}

Figure 1. Percentages received on Daily Progress Report Cards ................................... 18 


\begin{abstract}
An educational framework known as School Wide Positive Behavior Support being implemented in school systems across the country provides the schools with three tiers of support to address both academic and behavior challenges. The purpose of this study was to evaluate the use of peer tutors when applied to a Tier 2 intervention known as Check-In Check-Out (CICO). Peer tutors performed the morning check-in with the tutees by setting the expectations for the day and giving the tutees their Daily Progress Report (DPR) form. Throughout the day, the tutees took the DPR form to each class where they received a score from the teacher. At the end of the class period, the peer tutors provided the tutees with feedback on the scores received on the DPR form. Once the school day finished, the peer tutees checked-out with the tutors and received a reward if they met their percentage goal. The results of this study showed that CICO implemented by peers improved classroom behavior for all three participants.
\end{abstract}




\section{Introduction}

In 2004, Congress established the Individuals with Disabilities Education Improvement Act (IDEA, 2004), which required that children with disabilities in the school systems be provided with an Individualized Education Program (IEP) based on peer-reviewed research (PRR) methods (Etscheidt \& Murran, 2010). An educational framework known as School Wide Positive Behavior Support (SWPBS) is now being utilized in several schools nationwide to address academic and behavior problems in the school system. This approach employs three tiers of support, which emphasize creating and teaching school wide expectations, providing clear consequences for appropriate and challenging behaviors, and making data driven decisions (What is School Wide Positive Behavioral Interventions and Supports, 2012).

These school wide interventions have proven to be effective for $80-85 \%$ of the students, with the remaining $15-20 \%$ requiring more intense and individualized help. Interventions targeted for that population fall under the second tier of SWPBS. Although countless research studies have outlined the importance of pinpointing the function of behaviors before designing intervention plans (e.g. Carr, 1977; Carr, Newsom, \& Binkoff, 1980; Iwata, Dorsey, Slifer, Bauman, \& Richman, 1994), the goal of SWPBS Tier 2 interventions is to help a group of students within $72 \mathrm{hr}$ of being selected for the program, therefore, it is not be feasible to conduct a functional assessment before 
implementing the program (March \& Horner, 2002). A Tier 2 intervention is expected to be cost effective, require no more than $10 \mathrm{~min}$ at a time, and be immediately accessible to any student that needs it (McIntosh, Campbell, Carter, \& Dickey, 2009).

A common Tier 2 intervention used in schools is Check-In Check-Out (CICO), also called the Behavior Education Program (BEP). This intervention provides the students with direct instructions that closely match the school wide expectations and allows them to contact reinforcement on a more frequent schedule (McIntosh et al., 2009). CICO requires that students check-in in the morning with the designated coordinator where they receive the daily points card and are asked to demonstrate their readiness for school. The points card includes the number of opportunities the students have that day to receive feedback and earn points contingent on engaging in appropriate behaviors. Throughout the day, the students' teachers are in charge of awarding them points for the behaviors they engaged in. These points are then recorded in a daily progress report (DPR) card that includes a 3-point scoring criterion - 0 (did not meet expectations), 1 (somewhat met expectations), or 2 (met expectations) to mark the students' progress on the DPR. At the end of the school day, the student meets once again with the CICO coordinator for the check-out session where together they evaluate the feedback provided to the student (Campbell \& Anderson, 2011).

Because teachers have been the ones responsible for implementing CICO, it is important to analyze its social validity and whether this intervention is only effective with maximum participation from the researchers, as has been the case in most CICO studies. According to Fairbanks, Sugai, Guardino, and Lathrop (2007), teachers considered CICO to be easy to carry out and implemented it on their own with high fidelity. Filter et al. 
(2007) evaluated the treatment integrity of a CICO program implemented by school personnel with the natural supports provided by the school district instead of the researchers. Students in three elementary schools participated in this study based on criteria determined by the school administrators. The authors measured the fidelity of implementation of the CICO program, the number of referrals, and the social validity of the program. Results suggest that when the CICO program was in effect, there was a decrease in office referrals for most participants, and not only did school personnel perceive the program as effective, they also implemented it with high fidelity on their own.

Simonsen, Myers, and Briere (2011) compared the effects of CICO and regular instruction on problem behavior. Results suggest that students who received the CICO intervention engaged in much less problem behaviors and reported more academic gains than did those receiving regular instruction. Hawken, McLeod, and Rawlings (2007), also found positive results with 11 regular education students and one special education student at an elementary school. In this study, the authors evaluated the effects of implementing the CICO program on office discipline referrals. The results of this study show a decrease in office referrals and an increase in class participation by all students. Similar results were attained by Todd, Campbell, Meyer, and Horner (2008) and March and Horner (2002). A limitation noted in these studies has been the difference in effectiveness of CICO with some students. Fairbanks et al. (2007) evaluated the effectives of CICO on the behavior of 10 second grade students who were nominated by their teachers due to their engagement in problem behaviors in the classroom. The results of this study indicated that after the implementation of CICO problem behaviors 
decreased for all the students, however not all reached criterion levels and some required more individualized planning. The students who reached criterion engaged in attention maintained problem behaviors and those who required extra help engaged in escape maintained problem behaviors. Another study by McIntosh et al. (2009) achieved similar results, which suggests that although all children benefitted from the intervention, those children whose behaviors were maintained by attention achieved greater gains.

Because Tier 2 interventions are required to operate on minimal resources but at the same time be fast, easy, and effective it is important to identify ways to achieve this. Peer tutoring has been used as an instructional method in which some students provide the instructions to other students as a way to make intervention more efficient and accessible. This method of instruction has been used in both elementary (e.g., Nelson, Johnson, \& Marchand - Martella, 1996) and middle school (e.g., Allsopp, 1997) settings. Peer tutoring can take place with more knowledgeable students teaching other students in the same grade level (heterogeneous groups), students teaching others who possess similar skills (homogeneous groups), older students teaching younger students (cross-age groups), and students classified with a disability providing tutoring to other students who may or may not have a disability (reverse - role) (Utley, Mortweet, \& Greenwood, 1997).

Mastropieri et al. (2001) compared traditional instructional techniques to peer tutoring for teaching reading comprehension to middle school students diagnosed with intellectual and learning disabilities. The results of this study showed that students in the peer tutoring conditions scored higher than students in the "business as usual"/regular education group on a posttest designed to evaluate reading comprehension. Students also suggested that peer tutoring had been an enjoyable activity, however, they had a difficult 
time providing corrective feedback to their partners. These results are consistent with a literature review of peer tutoring by Stenhoff and Lignugaris/Kraft (2007), which suggested that in order for peer tutoring to be effective, it is important for peer tutors to be trained to provide feedback, correct errors made by the peers, and monitor progress. It is also important for teachers to frequently monitor tutors' implementation so as to provide reinforcement and corrective feedback when necessary. Other studies have shown that academic benefits from peer tutoring are not only exhibited by the tutees but also by the peer tutors (e.g., Dineen, Clark, \& Risley, 1977). Social (Franca \& Kerr, 1990) and behavioral (DuPaul, Ervin, Hook, \& McGoey, 1998) benefits experienced by both have also been mentioned in the peer tutoring literature. Franca and Kerr (1990) tracked the rate of correct and incorrect responses in a math worksheet for both tutors and tutees. The tutors' responsibilities were to provide instructions, corrective feedback, and reinforcement. The data show that not only did the tutees improve, but also immediately after becoming tutors, the rate of correct responding in math worksheets increased for all students. Peer tutoring has also been used to teach math (Tsuei, 2012), vocabulary (Hogan \& Prater, 1993), social studies (e.g., Mastropieri, Scruggs, Spencer, \& Fontana, 2005) and safety skills (e.g., Jostad, Miltenberger, Kelso, \& Knudson, 2008).

For peer tutoring to fit the Tier 2 intervention expectations, it's important to determine the level of supervision required for peer tutors to implement programs with fidelity with minimal intrusions by adults and/or researchers. Dufrene et al. (2010) identified peer tutoring as an economical means of instruction in which students collaborate on school assignments. These authors conducted a study in which peers worked with students to implement and monitor fluency-based training for reading. 
Results for this study showed that peer tutors implemented the program with high fidelity and peer tutees increased their reading fluency. Comparable results have been demonstrated by Dufrene, Henington, and Townsend (2006) and Yurick, Robinson, Cartledge, Lo, and Evans (2006).

According to the results of the peer tutoring literature, peer tutoring is a beneficial method of providing academic instruction to both typically developing children as well as children in special education classrooms. It is also reported that peer tutoring helps students achieve greater scores academically, engage in more on task behaviors, and engage in appropriate social interactions while being a method that is preferred by teachers (Mastropieri et al., 2001). Including peers in the CICO process may be a beneficial addition to this widely used Tier 2 intervention because it may decrease the number of school staff necessary to implement CICO and therefore further decrease the resources required for its implementation. The purpose of this study was to evaluate the implementation of CICO with peer tutors in an elementary school currently labeled as a PBS school but not implementing any aspects of the PBS approach with fidelity. 


\section{Method}

\section{Participants and Settings}

All sessions took place at a local elementary school in Tampa, FL. This school is classified as a Renaissance school and is home to about 620 students from Head Start to fifth grade. A school is deemed a Renaissance school when $90 \%$ or more of its student population receives free or reduced lunch. This school has also received some of the lowest reading scores in the entire state.

The participants for this study were five, fourth-grade students ages 8-10. Two of the students participated as the peer tutors and the other three participated as the tutees. All participants were placed in a regular education classroom the entire day, however, a reading aid assisted A.W during his afternoon reading class. At the time the study took place, classroom rules had been developed by the teacher, but according to direct observations, these rules were not frequently instructed to the students. All students in the classroom, including the tutees were observed to engage in similar problem behaviors, including disrespect, fighting, and inappropriate behaviors as labeled by the teacher.

Students were selected by the teacher using the Teacher Nomination Form (Teacher Nomination Form, 2007) provided to them (see appendix A for teacher nomination form). The inclusion criteria for tutees were having attention maintained problem behaviors of concern, being fully verbal, and being able to follow instructions. 
Students did not need to have a standing DSM diagnosis in order to participate in this study.. Peer tutors were students who engaged in the appropriate behaviors outlined for the classroom, had all the same classes as the tutees, and were able to provide other students with instructions and feedback.

Once students were nominated to participate in this study, a functional behavior assessment was completed to determine if their problem behaviors met the criteria for participation in this study. If so, individual meetings were held with both the student and the parent to explain the study in detail and offer them the choice to participate. No extra credit or special privileges were offered to any of the students for participating in the study. An assent form was given to each student once he agreed to take part in the study and the parents and teachers were asked to complete a consent form. Once everyone agreed to participate in the study, a daily points goal was established in which the student must earn at least $80 \%$ of the total possible points in one day in order to receive the reward at the end of the day.

\section{Functional Behavior Assessment}

Once students were nominated by the teachers as having problem behaviors of concern a functional behavior assessment was started to identify the function of the students' problem behaviors. This process involved interviews and direct observations of the child in the classroom. Interviews consisted of a meeting with the teacher in which the students' problem behaviors were identified and described. The teacher was also asked to provide examples of when the student typically engaged in these behaviors, the consequences of the problem behaviors, any setting events they were aware of that increased the probability that a student would engage in problem behaviors (not receiving 
teacher attention for a while) and times of days in which problem behaviors were more likely to occur (see B for interview questions).

Once the initial interview was completed and the information suggested an attention function for the problem behavior, direct observations occurred in which a trained researcher inconspicuously collected ABC data on the student's problem behaviors. Direct observations took place in the classroom during varying times of the day. An $\mathrm{ABC}$ recording chart was used for every observation (see appendix $\mathrm{C}$ for $\mathrm{ABC}$ chart). In the chart, the researcher recorded antecedent events that occurred prior to the problem behaviors, a detailed description of the student's behaviors, and any teacher responses that followed the problem behavior. Recording took place until a discernible pattern emerged in the data with teacher attention being recorded as the predominant consequence of the behavior (suggesting an attention function)

Following the completion of the interview and direct observations, the results were evaluated by the researcher. The evaluator determined common antecedent events that reliably precede problem behaviors. Responses following challenging behaviors were also analyzed to determine if teacher attention was the main consequence.

Only those students who had interview and observation results suggesting attention maintained behaviors of concern were be asked to participate in this study.

\section{Data Collection and Interobserver Agreement}

Data collection for the Functional Behavior Assessment occurred as described above. Data for the evaluation of CICO was collected in one of the student's current classrooms. Because students switched classrooms in the middle of the day and only one of the students' teachers chose to participate, data were collected for only half of the day 
in one specific classroom. The student's day with the participating teacher was divided into the naturally occurring time intervals provided for the class and data were collected on the percentage of points received on the Daily Progress Report (DPR) form. The target behaviors outlined in the DPR form were derived from the classroom rules developed by the teacher. These behaviors were: using nice and appropriate words, using hand signals, listening to the teacher before asking questions and remaining quiet with body and words. Discipline referrals were a secondary variable that was monitored. These secondary data were collected throughout the duration of the study by meeting with a school administrator who had access to such documentation.

Interobserver agreement (IOA) on the score received in the DPR form was collected at least $33 \%$ of all the days. An independent observer was present during one of the class periods and used a DPR form identical to the one being used by the teacher to score the interval. Because the progress report card provided four opportunities for scoring (four appropriate behaviors the students had the opportunity to engage in during each interval), IOA was measured by calculating the percentage of agreement in the interval. This was done by dividing the number of appropriate behaviors both the teacher and the observer scored the same by the total number of appropriate behaviors possible. IOA was calculated by adding the percentages for all the sessions in which IOA was collected and dividing it by the total number of sessions for all the participants. IOA for this study was $84.2 \%$. Mean IOA for A.W was $75 \%$ with a range of $25-100 \%$. The mean percentage was $87.5 \%$ for C.C with a range of $75-100 \%$, and $90 \%$ for X.J with a range of $75-100 \%$. 


\section{Design}

A multiple baseline design across participants was used to evaluate the effectiveness of treatment in this study. Following baseline, the CICO with peer tutors procedure was implemented in a staggered fashion across all the students. An embedded $\mathrm{ABC}$ design was used to evaluate if DPR scores maintained following the fading plan (further explained below) for two of the students.

\section{Procedure}

Once the participants were referred for inclusion in the study, the Functional Behavior Assessment began. Students whose problem behaviors were maintained by attention were assessed in baseline and then moved to the CICO Peer phase. Once students met the criteria for termination of this phase, the fading plan was started.

Baseline. During baseline, the teacher was provided with the DPR forms and told to score each student in every class period. No feedback was provided to the student by the teacher or peer tutors.

Check-in check-out - peer. A peer tutor and tutee arrived at the school prior to the start of the first period class. Both students met in a designated area in the classroom where the peer tutor provided the tutee with a Daily Progress Report (DPR) form (see appendix D for DPR form) that was divided into the student's class periods. The tutees were expected to carry this form with them throughout the entire time they were in class with the participating teacher. During this initial check-in, the students were asked to demonstrate that they were ready to begin the day by showing the tutors their notebooks and pencils/pens. The tutees were also asked to turn in the previous day's DPR form signed by the parents and were given praise for doing so. If a student did not bring the 
signed form, the tutor reminded him to do so the next day. The tutees were also asked to identify specific goals and appropriate behaviors to engage in during the day and were provided with feedback by the tutors.

At the beginning of each period, the peer tutors reminded the tutees of the classroom rules for that day. Classroom rules were broken down into appropriate behaviors for all the students. Because all three participants were in the same teacher's classroom in the morning or in the afternoon, the teacher selected the same appropriate behaviors for all of them to work on based on her classroom rules. A.W met with this teacher for the afternoon session and both C.C and X.J were in the teacher's morning session. The tutees then kept their DPR form at their desk and the teacher was in charge of observing the student's behaviors throughout the class period. At the end of the class period, the teacher scored each student on all four appropriate behaviors he was expected to engaging in, awarding him with a "0" if he did not meet the classroom expectations, " 1 " if he somewhat met the expectation, and "2" if the he met the class expectations. At the end of the class period, the teacher met briefly with the tutee and provided him with feedback on the scores he received. The peer tutor was also present during this interaction. If a student received a score of " 0 ," the teacher let the tutee know which behaviors he engaged in that were inappropriate and encouraged him to do better during the next class period. If the tutee received a " 1 ," the teacher provided praise for appropriate behaviors and followed the same protocol listed above for inappropriate behaviors, and if the tutee received a " 2 ," the teacher provided praise and encouraged the continuation of appropriate behaviors throughout the school day. Following this session, 
the peer tutor briefly encouraged the tutee to follow the expectations for the next class period.

It was noticed during the first days of intervention for A.W that the teacher was having difficulty meeting with him following each class period. It was also observed that the class was divided into two sections, with all the students engaging in appropriate behaviors in one section and all students who engaged in problem behaviors in the other section. A.W was seated at the very end of the section with the other students who engaged in inappropriate behaviors. Following a few days of observations, the researcher suggested that A.W be moved to the other section next to the peer tutor, with the rest of the students who engaged in appropriate behaviors, and a teacher-prompting program was started. During this time, the researcher came in the classroom each time the class periods ended and prompted the teacher to meet with the student and award him the points. Once the teacher was observed engaging in this behavior on her own, prompting was terminated. Because data suggested that A.W was still not meeting the points goal following the modification, a visual aid was used. The visual aid included the days of the weeks and the number of points received after each day, which the student could keep in his desk to remind him of how many points he received each day. He was told that he would earn a more preferred reinforcer at the end of the week if he met his points each day. Once this change didn't prove to be effective, all modifications were removed and the intervention continued as descried above.

At the end of the day, both the tutors and the tutees met once again in a designated place where the total daily points were calculated for the tutees. The daily points were then traded for tangible items such as candy, toys, or restaurant coupons. In order to earn 
these rewards, the tutees needed to earn the number of points agreed on at the initial meeting. If the students did not meet their daily points the peer tutor identified specific behaviors to work on the following school day. The tutors also gave the tutees their daily points card, which they were asked to bring back the next day with parental signature.

The percentage on the DPR form was analyzed daily to examine student progress. Students were deemed as making progress if they received $80 \%$ of their daily points total for five consecutive days.

Fading plan: Once students received at least $80 \%$ of their daily points for five consecutive days, a fading plan was started. The fading plan consisted of daily meetings with the peer tutors in the mornings and afternoons. The teacher scored the DPR form at the end of the day, right before the check-out time, but no longer held the feedback meetings following each class period. The tutees were still required to receive at least $80 \%$ of their daily points to receive a reward at the end of the day.

\section{Treatment Fidelity}

Treatment fidelity data were collected once each week to ensure appropriate participation from the peer tutors. A checklist with specific steps was used (see appendix E for checklist) to monitor the students. Monitoring occurred by directly observing each peer tutor providing the tutees with feedback. If the peer tutor received a score of less than $80 \%$ on the fidelity check, he met with the researcher and rehearsed the steps on the checklist. The peer tutor then engaged in role plays with the researcher on how to provide feedback. The need for peer tutor training only occurred once during the entire study. 


\section{Social Validity}

Following the completion of this study, the students and teacher completed a social validity questionnaire (see appendix $\mathrm{F}$ for social validity questionnaire). The questionnaire consisted of four questions for the peer tutors and tutees, and six questions for the teachers that helped identify if this procedure was well accepted and likely to be implemented in the future. It also helped identify any aspects of the procedure the students did not like. 


\section{Results}

Figure 1 shows participants' percentage on DPR forms in baseline, CICO with peer tutors, and the fading program. During baseline, the percentages on the DPR form were variable for all three participants ranging, from $0-87.5 \%$. The mean baseline score for A.W was $28.6 \%$ and his mean CICO score was $72.7 \%$. Although multiple modifications were added to his CICO program he only achieved the goal of $80 \%$ or above six times during the intervention and did not meet the goal established for progress or fading. It was noted however, that during the teacher prompting modification there was a slight decrease in variability in A.W's data. For C.C, baseline was highly variable with a mean of $54.9 \%$. His performance increased to a mean of $85 \%$ during CICO. Although he reached $80 \%$ or higher during three of 12 baseline sessions, he achieved $80 \%$ or above for five consecutive days during CICO and proceeded to fading. While in the fading phase, he attained the $80 \%$ goal 12 of 13 days with a mean score of $85.8 \%$. Although there is some overlap between baseline and intervention data, baseline was highly variable while the $\mathrm{CICO}$ and fading interventions produced stable data consistently above the $80 \%$ criterion The data for X.J were highly variable during baseline with an mean of $47.0 \%$. During intervention the mean increased to $86.9 \%$ with all sessions above the $80 \%$ criterion. Once in the fading program, the performance became highly variable and the mean dropped to $69.8 \%$. 
The number of discipline referrals given to each participant during the school year was recorded before and after intervention. Starting in January 2013, A.W received three discipline referrals for "disobedience and inappropriate behaviors." Following intervention, no more discipline referrals were given. C.C received his first referral in September of 2012, totaling five referrals for "inappropriate behavior, fighting and disrespect" by the time intervention was introduced. Following intervention, this number dropped to zero. X.J was not given any referrals the entire school year.

According to responses provided by the teacher on the social validity questionnaire, the maximum score of 5 was given to the first four questions. The teacher also mentioned she enjoyed seeing how interested her students were in participating in the intervention and receiving rewards at the end of the day. However, she believed the students were dependent on her attention and disliked this aspect of the intervention the most.

Responses by the students varied depending on the questions, but they were similar regardless of their role in the study. All students reported that they enjoyed working with their peer, assigning this question a score of 4 and 5 (mean $=4.5$ for peer tutors and 4.7 for tutees). When asked if they would do this study again, two participants - a peer tutor and a tutee - gave a 3, meaning neutral, but the rest of the participants scored this as 4 and 5 (Mean $=3.5$ for peer tutors and 4.3 for tutees). The tutees mentioned they enjoyed being able to communicate with the teacher and getting a reward when they met their point. One student reported that he did not like the days in which he wasn't able to earn a reward. The tutors wrote they enjoyed working with the peer and being able to give them rewards for meeting their points. 


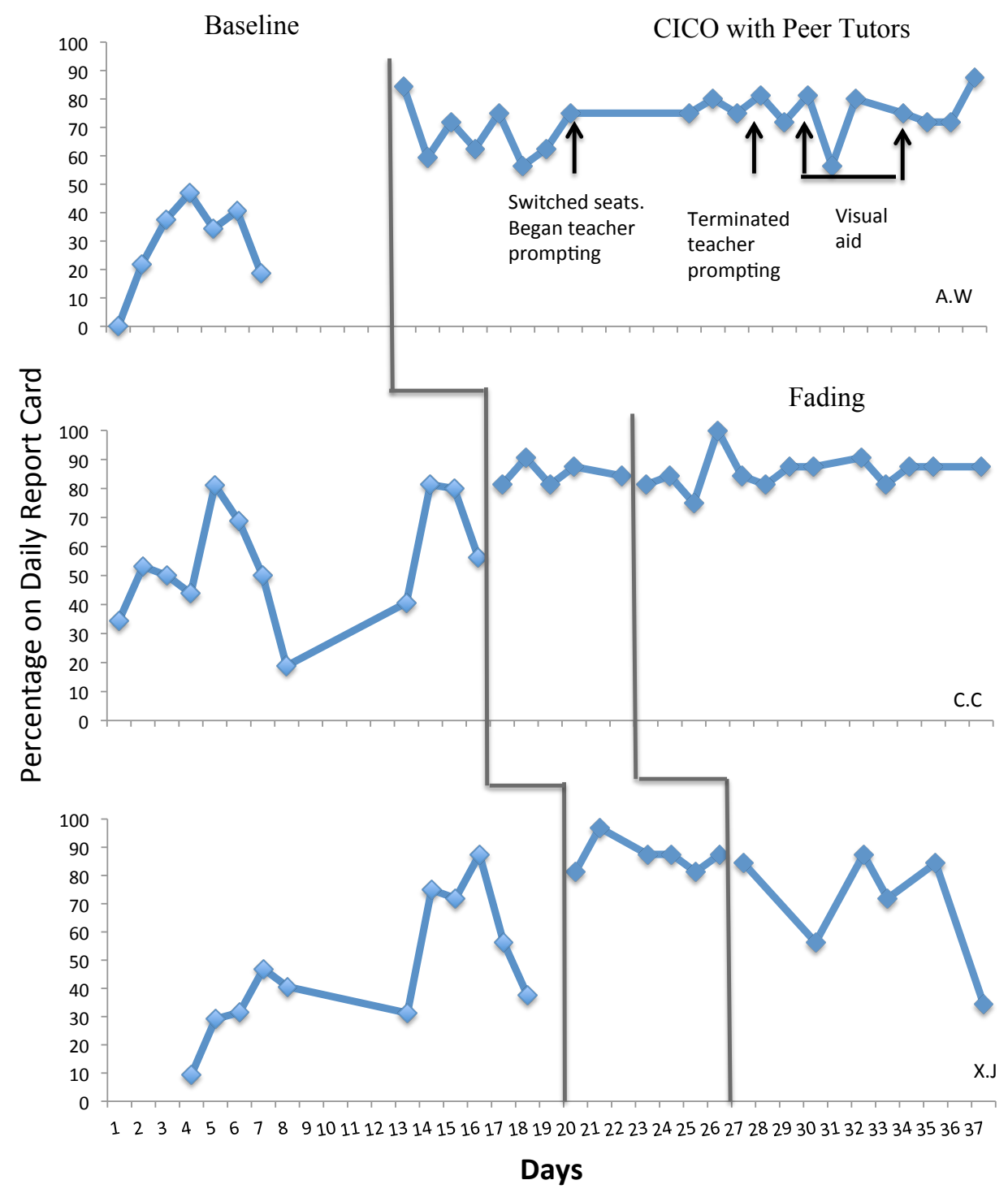

Figure 1. Percentages received on Daily Progress Report Cards during baseline and Check-In Check-Out with the peer tutors for three participants and fading for two of the participants. 


\section{Discussion}

As schools continue to implement the Positive Behavior Support framework, existing interventions are likely to evolve to decrease cost, response effort, and time required for implementation. The use of peer tutors in the CICO intervention may be a possible direction in which this intervention could advance. According to responses obtained in the social validity questionnaire, it seems that this procedure was well liked by both the teacher and students resulting in minimal response effort on the part of the teacher. The students also consistently reported that they liked working with their peer and most students said they would participate in this study again. Results of the present study show a substantial increase in percentage received in the Daily Progress Report form during the $\mathrm{CICO}$ with peer tutor phase, which resulted in C.C being chosen as a peer mentor of younger students at the school. This finding contributes to the literature by expanding on the effectiveness of CICO as a commonly used secondary intervention within a three-tiered system. With the addition of peer tutors, this intervention could become more feasible and consume less of the school staff's time. It also allows students to become more involved with the school's Positive Behavior Support framework. A functional relationship between the intervention and increase in the dependent variable can be seen by the immediate increase in and stability of percentages received in the Daily Progress Report form upon introduction of the intervention. It is important to note 
that, according to the Functional Behavior Assessment, attention was the primary function for all of the participants' problem behaviors in the classroom. Although escape was noted as a possible secondary function during observations, this was not the case for the majority of the problem behaviors exhibited by the students. The effectiveness of this intervention for students with attention maintained behaviors is consistent with the existing literature (Fairbanks et al., 2007; McIntosh et al., 2009).

It is also of relevance to explain that this intervention was conducted in the students' classroom by a teacher and two peer tutors in a school not currently implementing Positive Behavior Support or any other stable and effective behavior management program. This fact was obvious as the primary researcher completed an internship at this school and was aware of the lack of school wide procedures in place. The use of CICO with peer tutors in the absence of a school-wide behavior management program indicates that only the intervention was responsible for the increase in scores since other methods were not in place. When traditional CICO was proposed to the school staff, the main concern vocalized by most of the individuals was the time and cost associated with it. It was said that having a staff member working with students in the morning and afternoons would distract from the staff's primary responsibilities, a factor that was addressed in this modification of CICO by having peer tutors complete the morning and afternoon meetings. Also, the cost associated with the intervention was about $\$ 30$ in edibles and coupons the school received for free from preferred restaurants, which the students seemed to pick often. It was also observed that, although the teacher had difficulties with treatment fidelity at the beginning of the intervention with A.W, following prompting and fading she implemented the procedure throughout the remainder 
of the study with very high fidelity. Given all of this information, it can be suggested that this intervention can possibly by used as a stand-alone intervention in schools not currently implementing School Wide Positive Behavior Support. This procedure can be used as a resource for schools that are not interested in implementing the entire PBS framework but have a need for effective interventions that are low in cost and response effort. It is also possible that this intervention can be used solely by teachers in their classrooms since this was the case for this study.

It is important to consider the role of the peer tutor and the appropriateness of its use. As was the case in the study, the peer tutor was responsible for setting expectations, providing feedback at the end of the day based on the points awarded by the teacher, and giving the tutees a reward when they met the points. However, it must be noted that the peer tutors were not at all responsible for observing their peer's behavior. This distinction must be made because it would be inappropriate for the tutors to observe their peer's behaviors since this would distract from attending during class. The peer tutors also may not be capable of interpreting which behaviors are problematic and which ones are acceptable leading to confusion and lack of objectivity. It is also of significance to continue to explore the nature of the peer tutor in the context of a CICO intervention. Research mentions that both peer tutors and tutees can benefit from an intervention in which peer tutors are involved (e.g., Dineen, Clark, \& Risley, 1977) highlighting an interesting are for further investigation.

Although results suggest positive outcomes, several limitations should be noted. As was the case during this study, heavy researcher involvement was necessary due to the lack of implementation of PBS practices or any other effective behavior intervention 
school wide or in the classroom. Had this intervention taken place within an already existing PBS framework that was being implemented consistently and with fidelity, it is possible that researcher involvement could have been limited to occasional consultation. It is also possible that when implemented in a school utilizing the PBS framework the teacher-prompting phase of this intervention could have been avoided given that PBS encourages frequent positive interactions with students and well as Tier 2 supports, typically in the way of CICO. Also, The criteria used in this study for demonstrating progress was only five days at $80 \%$, an amount of time that can be considered short if using this intervention long term. Given the results demonstrated by the X.J during the fading phase, it is possible that his percentages would have dropped or at least been more variable over time regardless of the introduction of the fading procedure. The robustness of the effects of CICO over longer periods of time is something that can be evaluated in future studies. The overall IOA for this study was lower than hoped for, perhaps due to the subjectivity of the scoring system that left much room for variability. For example, the lowest IOA score for A.W was $25 \%$, meaning that during that particular day, the teacher and observer only agreed on scoring one of the four possible behaviors the participant could engage in. Future research should look at developing a more objective scoring regimen for $\mathrm{CICO}$. Also, although results suggest an increase in daily percentages and a complete cessation in discipline referrals, data were not gathered on specific problem behaviors and so it cannot be concluded that this intervention had an impact on the frequency, intensity, or duration of any particular problem behaviors exhibited by the students in the classroom. This study also took place during half the school day due to the 
other teachers' reluctance to participate in the study. It would be important to see if replication of these results can be obtained throughout an entire school day.

Another limitation in this study is that the initial goal for AW may have been too high. Based on the difficulty experienced by AW, the mean percentages received during baseline should be considered before setting a goal for intervention. In the case of A.W, it is possible that the intervention goal was too high, not allowing frequent contact with reinforcement. In this case, a changing criterion design with increasing goal levels might have been more beneficial. It is also obvious from the results that the fading program used in this study was not entirely effective. Although positive outcomes can be seen for C.C, X.J's results suggest that this was not the case for him. A few speculations can be made as to why this was so, such as increased absences during this phase interfering with the student's frequent contact with the intervention. It is also possible that the intervention should have been carried out longer for this student before moving on to the fading program. And lastly, another possibility may be that considering the student's primary function for problem behaviors was teacher attention, by removing this portion during fading, the intervention was no longer functionally equivalent and therefore unsuccessful. Although these are all speculations, the lack of success of the fading program is consistent with a study by Campbell and Anderson (2011), in which the complete removal of the teacher feedback session resulted in a decrease in academic engagement and a slight increase in intervals of problem behaviors. Finally, one more limitation of this study was the lack of generalization of appropriate behaviors to other classes. Observations conducted by the researcher show the students' other teacher still reported problem behaviors in her classroom even while the students were meeting their 
daily points in the intervention classroom. Analysis of generalization across classrooms is an issue that can also be evaluated in future projects.

Given the results obtained in this study and the response provided by the teacher and students in the social validity questionnaire, it is possible that utilizing peer tutors as the implementers of the CICO intervention may be a good way in which to decrease time and increase accessibility of this intervention. The use of peer tutors to implement CICO is promising and future studies should provide direct and systematic replications to demonstrate the robustness of the procedure. . 


\section{References}

Allsopp, D. H. (1997). Using class wide peer tutoring to teach beginning algebra problem solving skills to heterogeneous classrooms. Remedial and Special Education, 18, 367-379.

American Psychological Association. (2012). Facing the school dropout dilemma. Retrieved from http://www.apa.org/pi/families/resources/school-dropoutprevention.aspx

Campbell, A., \& Anderson, C. (2011). Check- In Check-Out: A Systematic evaluation and component analysis. Journal of Applied Behavior Analysis, 44, 315-326.

Carr, A. G. (1977). The motivation of self-injurious behavior: A review of some hypotheses. Psychological Bulletin, 84, 800-816.

Carr, E. G., Newsom, C. D., \& Binkoff, J. A. (1980). Escape as a factor in the aggressive behavior of two retarded children. Journal of Applied Behavior Analysis, 13, 101117.

Dineen, J. P., Clark, H. B., \& Risley, T. R. (1977). Peer tutoring among elementary students: Educational benefits to the tutor. Journal of Applied Behavior Analysis, 10, 231-238. 
Dufrene, B. A., Henington, C., \& Townsend, A. E. (2006). Peer tutoring for reading fluency: Student implementation and effects on reading fluency. Journal of Evidence Based Practice for Schools, 7, 118-137.

Dufrene, B., Reisener, C., Olmi, D., Zoder-Martell, K., McNutt, M., \& Horn, D. (2010). Peer tutoring for reading fluency as a feasible and effective alternative in response to intervention systems. Journal of Behavioral Education, 19, 239-256.

DuPaul, G. J., Ervin, R. A., Hook, C. L., \& McGoey, K. E. (1998). Peer tutoring for children with attention deficit hyperactivity disorder: Effects on classroom behavior and academic performance. Journal of Applied Behavior Analysis, 31, $579-592$.

Etscheidt, S., \& Murran, C. M. (2010). Reauthorization of the Individuals with Disabilities Education Improvement Act (IDEA, 2004): The peer-reviewed research requirement. Journal of Disabilities Policy Studies, 21, 29-39.

Fairbanks, S., Sugai, G., Guardino, D., \& Lathrop, M. (2007). Response to intervention: Examining classroom behavior support in second grade. Exceptional Children, $73,288-310$.

Filter, K. J., McKenna, M. K., Benedict, E. A., Homer, R. H., Todd, A. W., \& Watson, J. (2007). Check in/Check out: A post-hoc evaluation of an efficient, secondarylevel targeted intervention for reducing problem behaviors in schools. 2, 30, 6984.

Franca, V. M., \& Kerr, M. M. (1990). Peer tutoring among behaviorally disordered students: Academic and social benefits to tutor and tutee. Education and Treatment of Children, 13, 109-128. 
Hawken, L., MacLeod, S., \& Rawlings, L. (2007) Effects of the Behavior Education Program (BEP) on office discipline referrals of elementary school students. Journal of Positive Behavior Interventions, 9, 94-101.

Hogan, S., \& Prater, M. A. (1993). The effects of peer tutoring and self-management training on on-task, academic and disruptive behaviors. Behavioral Disorders, 18 , 118-128.

Iwata, B. A., Dorsey, M. F., Slifer, K. J., Bauman, K. E., \& Richman, G. S. (1994). Toward a functional analysis of self-injury. Journal of Applied Behavior Analysis, 27, 197-209.

Jostad, C. M., Miltenberger, R. G., Kelso, P., \& Knudson, P. (2008). Peer tutoring to prevent gunplay: Acquisition, generalization, and maintenance of safety skills. Journal of Applied Behavior Analysis, 41, 117-123.

McIntosh, K., Campbell, A., Carter, D., \& Dickey, C. (2009). Differential effects of a tier two intervention based in function of problem behavior. Journal of Positive Behavior Interventions, 11, 82-93.

March, R. E., \& Horner, R. H. (2002). Feasibility and contributions of functional behavioral assessment in schools. Journal Of Emotional and Behavioral Disorders, 10 (3), 158-170.

Mastropieri, M. A., Scruggs, T., Mohler, L., Beranek, M., Spencer, V., Boon, R. T.,...Talbot, E. (2001). Can middle school students with serious reading difficulties help each other learn anything? Learning Disabilities Research and Practice, 16, 18-27. 
Mastropieri, M. A., Scruggs, T., Spencer, V., \& Fontana, J. (2005). Promoting success in high school world history: Peer tutoring versus guided notes. Learning Disabilities Research and Practice, 18, 52-65.

Nelson, J. R., Johnson, A., \& Marchand-Martella, N. (1996). Effects of direct instruction, cooperative learning, and independent learning practices on the classroom behavior of students with behavioral disorders: A comparative analysis. Journal of Emotional and Behavioral Disorders, 4(1), 53-62.

Simonsen, B., Myers, D., \& Briere, D. (2011). Comparing a behavioral Check-In/CheckOut (CICO) intervention to standard practice in an urban middle school setting using an experimental group design. Journal of Positive Behavior Interventions, $13,31-48$.

Stenhoff, D., \& Lignugaris/Kraft, B. (2007). A review of the effect of peer tutoring on students with mild disabilities in secondary settings. Exceptional Children, 74, 830.

Todd, A., Campbell, A., Meyer, G., \& Horner, R. (2008). The effects of a targeted intervention to reduce problem behaviors. Journal of Positive Behavior Interventions, 10, 46-55.

Tsuei, M. (2012). Using synchronous peer tutoring system to promote elementary students' learning in mathematics. Computers and Education, 58, 1171-1182. doi:10.1016/j.compedu.2011.11.025

Positive Behavioral Interventions \& Supports. (2012). What is Schoolwide Positive Behavioral Interventions and Supports? Retrieved from http://www.pbis.org/school/what_is_swpbs.aspx 
Positive Behavior Support Project: A Multi-Tiered Support System (2007). Teacher Nomination Form. Retrieved from http://flpbs.fmhi.usf.edu/tier2/Teacher\%20Nomination\%20Form.pdf

Utley, C. A., Mortweet, S. L., \& Greenwood, C. R. (1997). Peer mediated instruction and interventions. Focus on Exceptional Children, 29, 1-23.

Yurick, A. L., Robinson, P. D., Cartledge, G., Lo, Y., \& Evans, T. L. (2006). Using peermediated repeated readings as a fluency building activity for urban learners. Education and Treatment of Children, 29, 469-506. 


\section{Appendix A}

\section{Teacher Nomination Form}

School:

Teacher:

Grade(s):

Type of Class (e.g., regular ed., reading):

Date:

The first step is to identify all students in your class or across your day who are of concern to you on two categories of inappropriate behavior: externalizing and internalizing behaviors.

If you are a middle school, high school, specials, or any other type of teacher who interacts

with hundreds of students throughout the day, you will identify the top students across your

day rather than by class or period.

Externalizing behaviors are those behaviors that are displayed outwardly by the child towards

an external social event in the environment. Externalizing behaviors typically occur too often or too much. Examples include aggression towards people, animals, or things; arguing; defiance; out of seat; calling out; tantrums; non-compliance; hyperactivity; stealing; and not following directions.

Internalizing behaviors are those behaviors that are displayed inwardly towards the self. Internalizing behaviors typically are self-imposed, do not occur frequently enough, and appear

to allow the student to avoid social events. Examples include not interacting with other people, overly shy or timid, withdrawing or avoiding social situations, fearful; and not standing up for one's self. 
Examples of externalizing behaviors: behaviors:

- Aggression to others or things

- Hyperactivity

- Non-compliance

- Disruptive

- Arguing

- Defiance

- Stealing

- Not following directions

banging)

- Calling out
Examples of internalizing

- Exhibits sadness or depression

- Sleeps a lot

- Is teased or bullied by peers

- Does not participate in games

- Very shy or timid

- Acts fearful

- Does not stand up for self

- Self-injury (cutting self, head

- Withdrawn

Step 1) Using student initials, list at least 5 students and no more than 10 students in your class or throughout your day who exhibit externalizing or internalizing behaviors. You do not have to list them in order.

Student Initials Grade/Period I or E (Step 2) Student Initials Grade/Period I or E (Step 2)
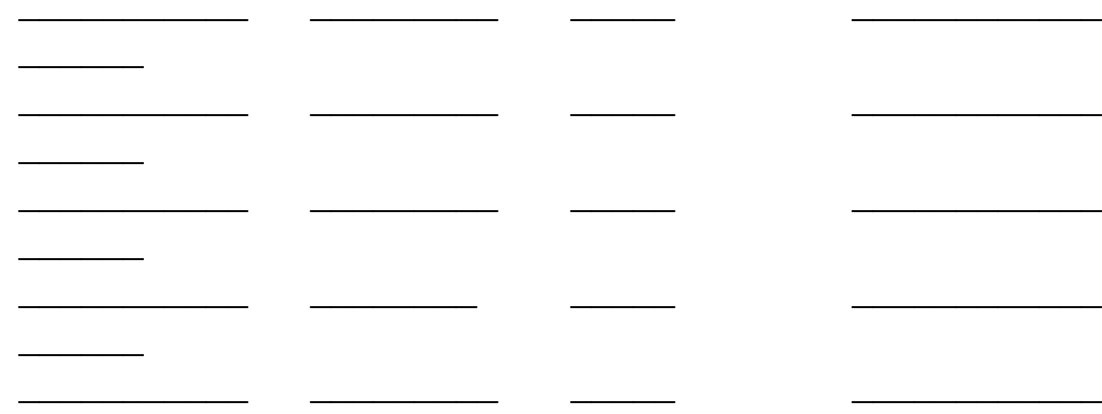

Step 2) Go back to your list generated above and write an "E" next to students who exhibit

externalizing behaviors and an "I" next to students who exhibit internalizing behaviors.

Step 3) Using your list generated above, rank no more than your top three externalizing students and your top three internalizing students below. Please use student initials.

Check "YES" if you have personally taught the expectations to the student. "Personally 
taught"

is defined as: Having discussed each school-wide expectation one-on-one with the student, after

which the student demonstrates an understanding of each of the concepts.

Check "YES" if you have personally given a School-wide PBS reward to the student.

Given

Academic Personally Taught Personally

$\begin{array}{lll}\text { Externalizing Concerns } & \text { Expectations }\end{array}$

Reward

1. _ Yes Y Yes

2. - Yes - Yes

3. $\longrightarrow$ Yes $\longrightarrow$ Yes

Yes

Yes

Yes 


\section{Appendix B}

1- Questions about the problem behavior

a. Please describe the behavior (continue with questions until a complete description is gathered)

b. Please describe any sequences (continue with questions until a complete description is gathered)

2- Questions about antecedents

a. When does the behavior occur? Where does the behavior occur/ who is present? What is going on when the behavior occurs? (continue until a complete description of antecedents)

3- Questions about consequences

a. What happens right after the problem behavior occurs? What do you do or say? How does the teacher's aide react? How do other students react? Do these behaviors occur in a predictable way? Always following a specific task, demand, situation, etc.? (continue with questions until a complete description of consequences) 
Appendix C

\begin{tabular}{|l|l|l|l|}
\hline Date & Antecedent & Behavior & Consequence \\
\hline & & & \\
\hline & & & \\
\hline & & & \\
\hline & & & \\
\hline
\end{tabular}




\section{Appendix D}

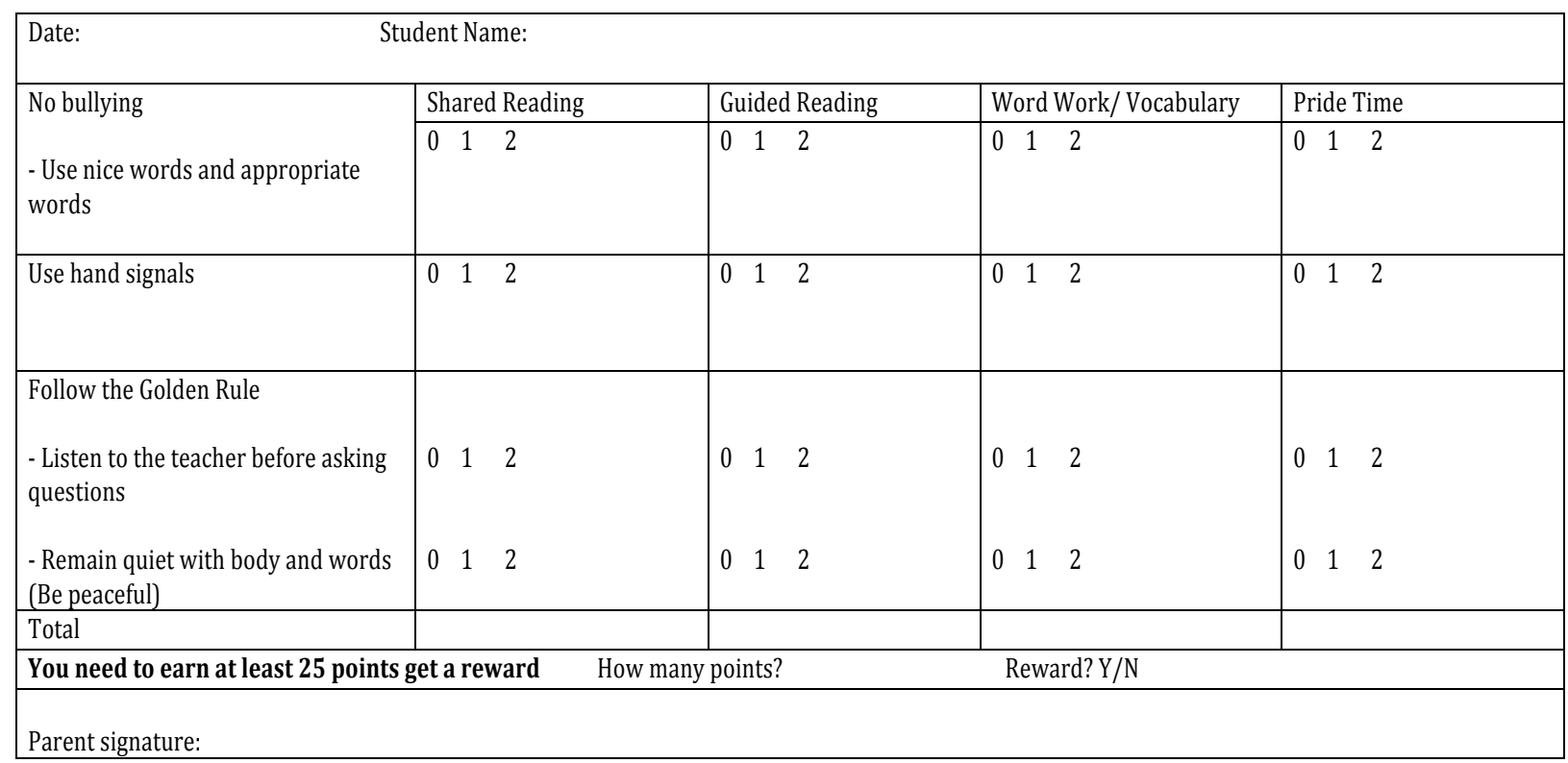


Appendix E

\begin{tabular}{|l|l|}
\hline \multicolumn{2}{|c|}{ Morning Check - In } \\
\hline Provide the student with DPR & \\
\hline Ask if he's ready for the day. If materials & \\
are needed let teacher know. & \\
\hline Ask student to turn in last night's card & \\
\hline Check card is signed & \\
\hline If signed, provide with praise & \\
\hline If not signed, remind student to bring it & \\
\hline signed for the next day & \\
\hline Ask student to identify goals for the day & \\
\hline Score & \\
\hline
\end{tabular}




\begin{tabular}{|l|l|}
\hline \multicolumn{2}{|c|}{ End of day Check-Out } \\
\hline Behaviors & Yes/No \\
\hline Calculate daily points total & \\
\hline Check the student met the points & \\
\hline If points are met, provide with praise & \\
\hline Allow student to choose reward & \\
\hline If points not met, provide with specific \\
behaviors to work on for the next day
\end{tabular}




\section{Appendix F}

\section{My role in this study was: Peer tutor/ Peer tutee}

1- I liked working with my peer

$\begin{array}{ccccc}\text { Strongly Disagree } & \text { Disagree } & \text { Neutral } & \text { Agree } & \text { Strongly Agree } \\ 1 & 2 & 3 & 4 & 5\end{array}$

2- I would do this again

$\begin{array}{ccccc}\text { Strongly Disagree } & \text { Disagree } & \text { Neutral } & \text { Agree } & \text { Strongly Agree } \\ 1 & 2 & 3 & 4 & 5\end{array}$

3- What did you like the most?

4- Was there anything you didn't like? 


\section{Teacher Social Validity Form}

1- I liked participating in this study.

$\begin{array}{ccccc}\text { Strongly Disagree } & \text { Disagree } & \text { Neutral } & \text { Agree } & \text { Strongly Agree } \\ 1 & 2 & 3 & 4 & 5\end{array}$

2- I feel that my student's behavior improved following the intervention in this study.

$\begin{array}{ccccc}\text { Strongly Disagree } & \text { Disagree } & \text { Neutral } & \text { Agree } & \text { Strongly Agree } \\ 1 & 2 & 3 & 4 & 5\end{array}$

3- This intervention was easy to implement.

$\begin{array}{ccccc}\text { Strongly Disagree } & \text { Disagree } & \text { Neutral } & \text { Agree } & \text { Strongly Agree } \\ 1 & 2 & 3 & 4 & 5\end{array}$

4- I would participate in another study similar to this one again.

$\begin{array}{ccccc}\text { Strongly Disagree } & \text { Disagree } & \text { Neutral } & \text { Agree } & \text { Strongly Agree } \\ 1 & 2 & 3 & 4 & 5\end{array}$

5- What did you like the most?

6- What did you like the least? 